\title{
OPEN Effects of GLP-1 receptor agonist on changes in the gut bacterium and the underlying mechanisms
}

\begin{abstract}
Shunsuke Kato ${ }^{1}$, Takehiro Sato ${ }^{1}$, Hiroki Fujita ${ }^{1}$, Masahiro Kawatani ${ }^{2,3}$ \& Yuichiro Yamada ${ }^{1,4 凶}$
There is a close relationship between the gut microbiota and metabolic disorders. In this study, acute administration of the glucagon-like peptide-1 receptor agonist (GLP-1RA) liraglutide to mice increased the cecal levels of caseinolytic protease B, a component of Escherichia coli, and of norepinephrine. Chemical sympathectomy blocked these events. Norepinephrine was found to pass into the intestinal lumen in vitro. c-Fos staining of the intermediolateral nucleus was identified as indirect evidence of sympathetic nervous system activation of the intestinal tract by GLP-1RA. Under normal conditions, the increase in E. coli did not affect the host. However, in mice with colitis, bacterial translocation was observed with attenuation of tight junction gene expression. This is the first study to investigate the unique underlying mechanisms related the effects of GLP-1RA on changes in the gut bacterium.
\end{abstract}

The gut microbiota exerts various effects on the host and is associated with several diseases ${ }^{1}$. For example, butyrate producing bacteria and Akkermansia are decreased in type 2 diabetes mellitus patients ${ }^{2}$. It has been reported that the intestinal environment (bacteria and viruses) changes even before the onset of type 1 diabetes mellitus (T1DM) and that there are bacteria that inhibit the onset of T1DM ${ }^{3-5}$. Meanwhile, anti-diabetic drugs have been reported to alter the structure of the gut microbiota. There are reports of beneficial changes in the gut microbiota by biguanides, but few other anti-diabetic drugs are reported ${ }^{6-8}$.

Escherichia coli (E. coli), one of the most famous bacteria of the gut microbiota, is a usually harmless resident bacterium. However, some E. coli strains can cause illness such as diarrhea ${ }^{9}$. An increase in E. coli has been reported in inflammatory bowel disease (IBD) patients ${ }^{10}$ and similar results have been found in a murine colitis model $^{11}$. Certain types of $E$. coli have been reported to activate host intestinal defense factors and inhibit the growth of other harmful gut bacteria, and their roles are expected to be diverse ${ }^{12,13}$.

The effects of E. coli components on the host have recently been reported. Caseinolytic protease B (ClpB), a component protein of $E$. coli, suppresses host appetite ${ }^{14}$. An increase in lipopolysaccharide (LPS) after eating has also been found to help to improve postprandial hyperglycemia ${ }^{15}$. On the other hand, there are reports that LPS reduces tight junction gene levels and promotes bacterial translocation, and that amyloid release from E. coli is involved in autoimmune diseases such as T1DM and systemic lupus erythematosus ${ }^{16-19}$. Thus, fluctuations in the levels of E. coli can be both beneficial and detrimental to the host.

Various factors are involved in the fluctuations and stabilities in bacterial levels, such as nutrient availability, temperature, osmolality, $\mathrm{pH}$, and bacteriophages, which are viruses that infect bacteria ${ }^{20-23}$. In addition, bacteria are regulated by host-derived neurotransmitters, hormones, and cytokines ${ }^{20}$. Norepinephrine (NE) has been reported to promote iron uptake in vitro, leading to the growth of $E$. coli ${ }^{20}$. Although NE is present in the intestinal lumen ${ }^{24}$, it is not clear whether NE in the intestinal tissue is released into the intestinal lumen and there appear to be no reports of NE-mediated increases in E. coli in vivo.

Gastrointestinal hormones that promote postprandial insulin secretion are collectively called incretins. There are two types: gastric inhibitory polypeptide (GIP), secreted from K cells present in the upper intestine, and glucagon-like peptide-1 (GLP-1), secreted from L cells present in the lower intestine and large intestine ${ }^{25}$. GLP-1 receptor agonists (GLP-1RAs) increase GLP-1 levels by 10 times or more and exert several pharmacological actions, including appetite-suppressant effects and delayed gastric emptying. The adverse effects of GLP-1RA, such as nausea, constipation, and diarrhea, are thought to be the result of the pharmacological action of GLP-1,

\footnotetext{
${ }^{1}$ Departments of Endocrinology, Diabetes, and Geriatric Medicine, Akita University Graduate School of Medicine, Akita, Japan. ²Departments of Neurophysiology, Akita University Graduate School of Medicine, Akita, Japan. ${ }^{3}$ Department of Neuroscience II, Research Institute of Environmental Medicine, Nagoya University, Nagoya, Japan. ${ }^{4}$ Kansai Electric Power Medical Research Institute, 2-1-7 Fukushima, Fukushima-ku, Osaka, Japan. ${ }^{\circledR}$ email: yyamada-dm@umin.ac.jp
} 
A
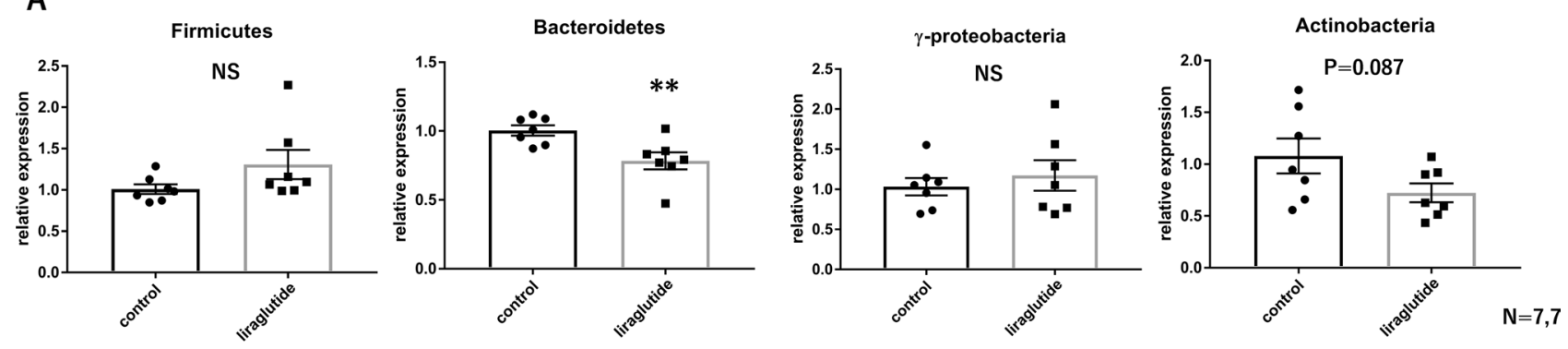

B

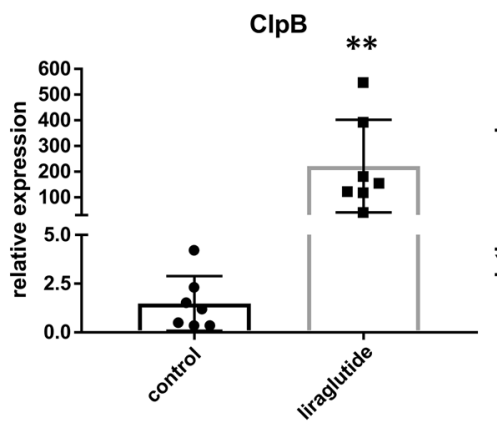

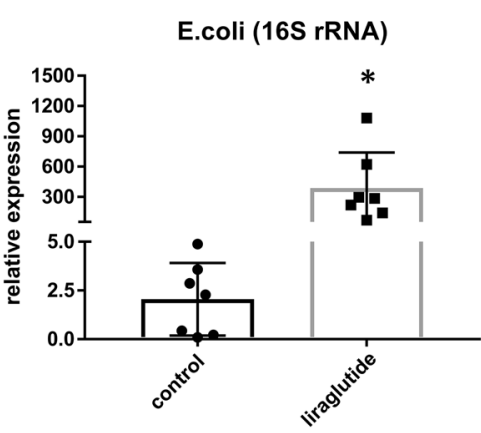

C

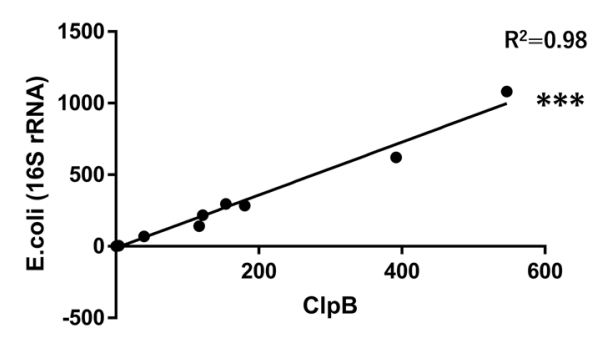

$\mathrm{N}=7,7$

$\mathrm{N}=14$

Figure 1. Acute administration of liraglutide increases E. coli levels in mice. Relative expression of (A) major gut microbiota (phylum level) and (B) ClpB and E. coli (16S rRNA) in cecal contents with or without acute liraglutide administration (control, $n=7$; liraglutide, $n=7$ ). $(\mathbf{C})$ Correlation between the relative expression of $\mathrm{ClpB}$ and E. coli $\left(16 \mathrm{~S}\right.$ rRNA) in cecal contents $(\mathrm{n}=14)$. All values represent the mean \pm SEM. ${ }^{\star} P<0.05,{ }^{* *} P<0.01$, ${ }^{* * *} P<0.001$; NS, not significant by non-paired t-test (A and $\mathbf{B}$ ) or linear regression analysis $(\mathbf{C})$. The coefficient of determination is denoted as $\mathrm{R}^{2}$. All figures were drawn using GraphPad Prism 7 (www.graphpad.com) and Microsoft's PowerPoint 2016 (www.microsoft.com).

but the mechanisms have not been fully elucidated. Nonetheless, GLP-1RA is known to affect the intestinal environment and, indeed, changes in the gut microbiota have been linked to GLP-1RAs ${ }^{26-28}$.

GLP-1RAs may directly or indirectly activate the sympathetic nervous system. One potential mechanism is thought to involve activation of the central nervous system, with the area postrema (AP) and nucleus of the solitary tract (NTS) and the intermediolateral nucleus (IML) of the spinal cord similarly activated by administration of GLP-1RA ${ }^{29,30}$. In general, GLP-1 is thought to have two effects, one exerted via the central nervous system and the other exerted via local receptors in the periphery. For example, GLP-1 may activate the heart, including the sinoatrial node, atrial cells, and ventricular cells, directly or indirectly through the sympathetic nervous system to increase the heart rate ${ }^{31,32}$. Similarly, two effects of GLP-1 on the gut must be borne in mind: sympathetic nervous system activation and direct effects on receptors in the gut tissue. In the latter, previous reports have shown that GLP-1R is involved in NO-mediated suppression of intestinal motility ${ }^{33}$. However, the relationship with intestinal NE and GLP-1 has not been clarified.

In this study, our hypothesis is that the increase in intestinal NE associated with sympathetic nervous system activation will play an important role in the association between the gut bacterium, especially E. coli, and GLP-1. We show the release of NE into the intestinal lumen in vitro and the activation of the sympathetic nervous system by acute administration of GLP-1RA with a concomitant rapid increase in E. coli in vivo. This is the first study to investigate the unique underlying mechanisms related the effects of GLP-1RA on changes in the gut bacterium.

\section{Results}

Acute administration of liraglutide increases E. coli levels in mice. After a single subcutaneous injection of liraglutide, a GLP-1RA, followed by a 16-h overnight fast, the relative expression levels of the gut bacterium in the cecal contents of mice were assessed using quantitative PCR. At the phylum level, liraglutide administration significantly decreased Bacteroidetes and tended to increase Actinobacteria (Fig. 1A). However, Firmicutes and Proteobacteria were not changed (Fig. 1A). At the genus level, liraglutide administration significantly reduced Ruminococcus and did not increase Akkermansia (Supplementary Fig. 1A).

We then compared the gene expression levels of bacterial proteins that could affect the host metabolism. Expression of formate-tetrahydrofolate ligase (FTHFS), which is related to acetic acid synthesis, was significantly increased and, conversely, the expression of butyryl-CoA: acetate CoA-transferase (BCoAT), which is related to butyrate synthesis, was significantly decreased (Supplementary Fig. 1A). We also showed that acute administration of liraglutide increased the expression of $\mathrm{ClpB}$ by about 400 -fold compared with the control (Fig. 1B). ClpB is encoded by several bacteria, but it is the ClpB from $E$. coli that affects host metabolism. To determine whether the expression of $\mathrm{ClpB}$ is truly related to E. coli number, we examined the $16 \mathrm{~S}$ rRNA expression of E. coli and 
A
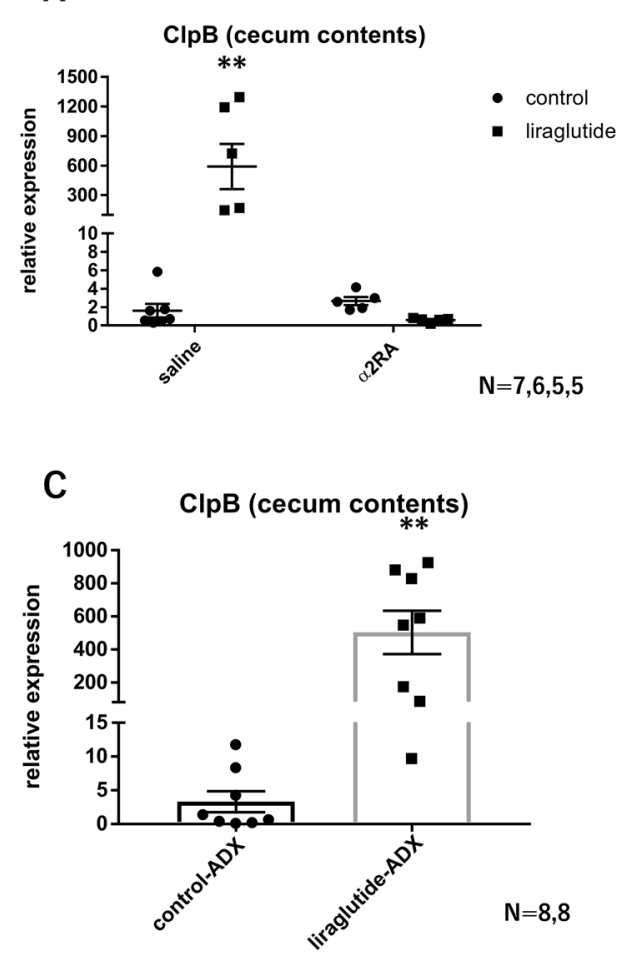

B

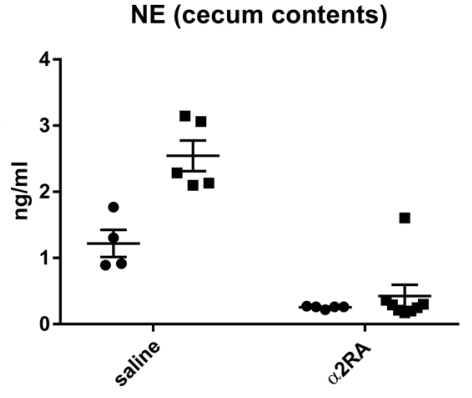

D

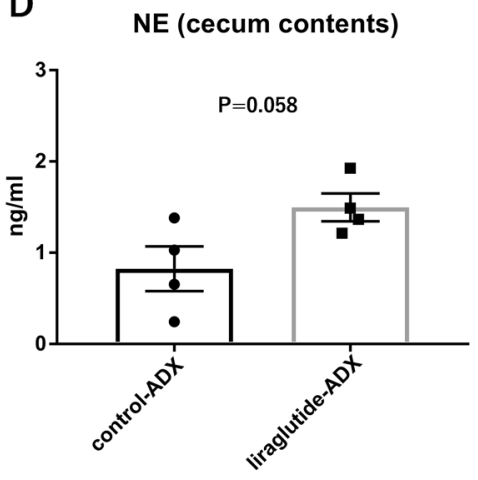

NE (plasma)

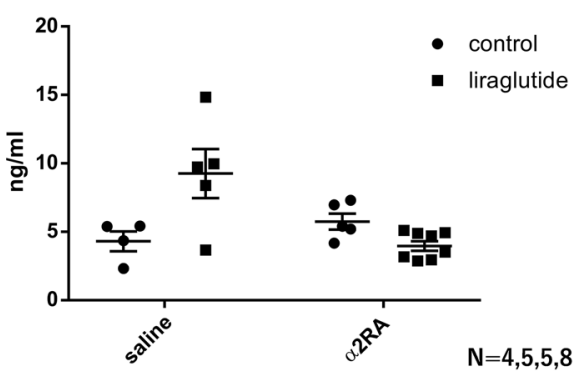

NE (plasma)

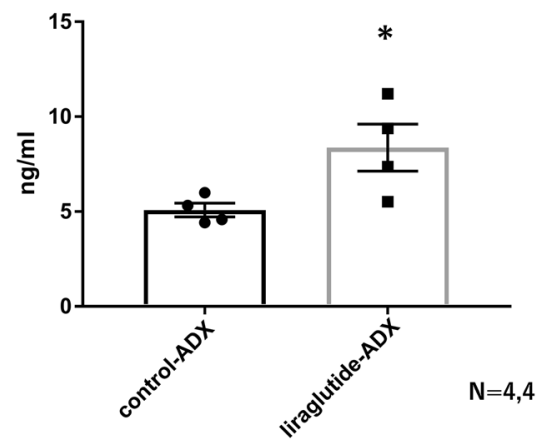

Figure 2. Liraglutide increases NE levels in cecal contents via activation of sympathetic nerves. (A) Relative expression of $\mathrm{ClpB}$ in cecal contents in saline and medetomidine ( $\alpha 2$ receptor agonist [ $\alpha 2 \mathrm{RA}]$ ) groups with or without acute liraglutide administration (saline control, $n=7$; saline liraglutide, $n=6$; $\alpha 2 R A$ control, $n=5 ; \alpha 2 R A$ liraglutide, $n=5$ ). (B) Measurement of norepinephrine concentrations in cecal contents and plasma in saline and medetomidine groups with or without acute liraglutide administration (saline control, $\mathrm{n}=4$; saline liraglutide, $n=5$; a2RA control, $n=5$; a2RA liraglutide, $n=8)$. (C) Relative expression of ClpB in cecal contents with or without acute liraglutide administration under bilateral adrenalectomy (ADX) (control-ADX, $n=8$; liraglutideADX, $n=8$ ). (D) Measurement of norepinephrine concentrations in cecal contents and plasma with or without acute liraglutide administration under ADX (control-ADX, $n=4$; liraglutide-ADX, $n=4$ ). All values represent the mean \pm SEM. ${ }^{\star} P<0.05,{ }^{* *} P<0.01,{ }^{* * *} P<0.001$; NS, not significant by two-way ANOVA with multiple comparison test (A and $\mathbf{B})$ or non-paired t-test $(\mathbf{C}$ and $\mathbf{D})$. All figures were drawn using GraphPad Prism 7 (www.graphpad.com) and Microsoft's PowerPoint 2016 (www.microsoft.com).

identified a significant positive correlation with ClpB (Fig. 1C). Thus, we have shown that acute administration of liraglutide increases $E$. coli levels in mice.

We also performed the experiment in the non-fasting condition. In the non-fasting condition, the expression of $\mathrm{ClpB}$ in the cecum contents was significantly higher in the liraglutide group. (Supplementary Fig. 1B). However, since liraglutide administration significantly reduced food intake (Supplementary Fig. 1C), we chose the fasting condition for this study. Also, in the present study, we focused in subsequent experiments on the dramatic elevation in $\mathrm{ClpB}$, as a marker of E. coli, induced by liraglutide administration.

Liraglutide increases NE levels in cecal contents via activation of sympathetic nerves. Next, we investigated whether sympathetic nervous system activation was involved in the increase in $E$. coli by examing levels of intestinal NE. We showed that acute administration of liraglutide significantly increased NE in both plasma and cecal contents (Fig. 2A). Then, administration of liraglutide with medetomidine, an a 2 receptor agonist, which suppresses the sympathetic nervous system, did not increase ClpB expression in cecal contents and NE levels in plasma and cecal contents (Fig. 2A,B). When liraglutide was acutely administered to bilaterallyadrenalectomized mice, NE levels in cecal contents tended to be increased and the expression of ClpB in cecal contents and NE levels in plasma were significantly increased (Fig. 2C,D). These results indicated that NE in cecal contents could be derived from sympathetic nerve terminals.

NE from sympathetic nerves passes into the intestinal lumen. We used a Ussing chamber to investigate whether the NE concentration on the mucosal side of the cecal tissue was increased by administration of drugs to the serosal side. A high concentration of $\mathrm{KCl}(60 \mathrm{mM})$ was administered to depolarize the cells, including the sympathetic nerve endings, and an increase in the NE concentration on the mucosal side was confirmed (Fig. 3A,B). We have recently reported the effect of carbachol on nicotinic receptors, and since nicotinic receptors are expressed at sympathetic synapses, we administered carbachol ${ }^{34}$. As a result, we found that carbachol 
A

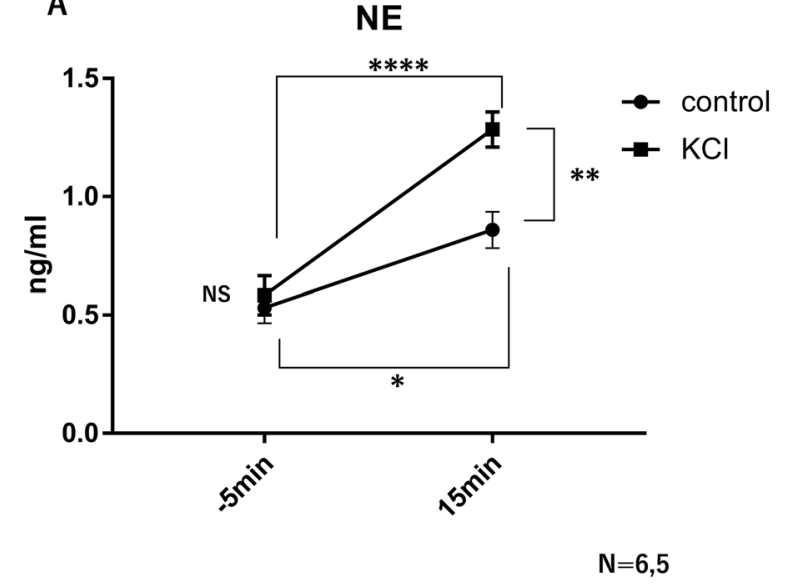

B

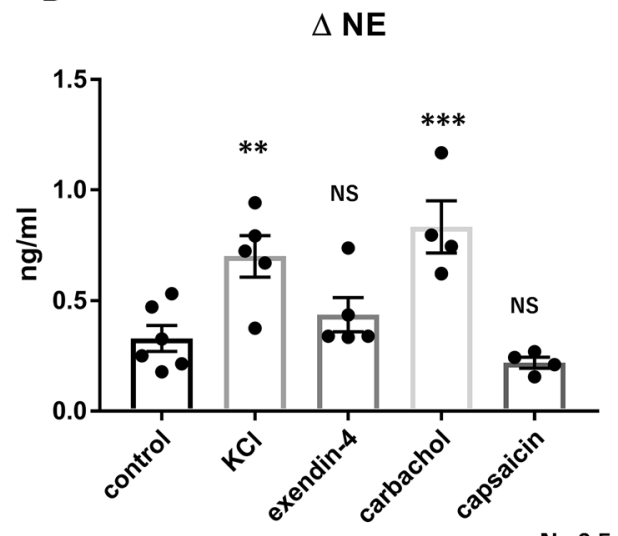

Figure 3. NE from sympathetic nerves passes into the intestinal lumen. (A) Measurement of norepinephrine concentration on the mucosal side before and after $\mathrm{KCl}$ administration to the serosal side of the cecum (control, $\mathrm{n}=6$; $\mathrm{KCl}, \mathrm{n}=5$ ). (B) Change in norepinephrine concentration on the mucosal side after the administration of various drugs to the serosal side of the cecum (control, $n=6 ; K C l, n=5$; exendin- $4, n=4$; carbachol, $n=4$; capsaicin, $\mathrm{n}=4$ ). All values represent the mean \pm SEM. ${ }^{\star} P<0.05,{ }^{* *} P<0.01,{ }^{* * *} P<0.001$; NS, not significant by two-way ANOVA with multiple comparison (A) or one-way ANOVA with multiple comparison (B). All figures were drawn using GraphPad Prism 7 (www.graphpad.com) and Microsoft's PowerPoint 2016 (www.microsoft. com).

administration increased the NE concentration. (Fig. 3B). GLP-1 receptors are expressed in the afferent branch of the vagus nerve and the enteric nervous system (ENS). However, activation of the afferent branch of the vagus nerve by capsaicin or activation of the vagus nerve and ENS by exendin-4, another GLP-1RA, failed to increase NE concentrations (Fig. 3B). These results indicate that NE in the intestinal tissue passes into the intestinal lumen and that GLP-1 acts more centrally.

Liraglutide enhances c-Fos staining, not only in the AP/NTS, but also in the IML. Because no direct peripheral effects of GLP-1RA were observed, we next examined its effects on the central nervous system. The brainstem nuclei, followed by preganglionic neurons in the IML, transmit postganglionic signals to the intestine. Two hours after liraglutide administration, c-Fos staining was clearly observed in the AP and NTS (Fig. 4A) and in the IML (Fig. 4B), suggesting that one mechanism by which GLP-1RA activates the sympathetic nervous system is a pathway involving the activation of the IML via the AP and NTS.

Increased expression of ClpB does not affect appetite. We next investigated the effects of a marked increase in $E$. coli in the gut on the host. ClpB has been reported to suppress appetite ${ }^{14,35}$. Liraglutide was administered to mice after suppression of the gut microbiota by antibiotics. The results showed that liraglutide had a significant appetite-suppressant effect, even in antibiotic-treated mice (Supplementary Fig. 2A,B). Next, the effect of appetite suppression was confirmed via fecal microbiota transplantation (FMT). Mice administered a single dose of liraglutide were used as donors, and antibiotic-treated mice were used as recipients. Recipient food intake during refeeding was then measured, but no significant difference was observed between the control and liraglutide-treated groups (Supplementary Fig. 2C). Therefore, the association between an increased expression of $\mathrm{ClpB}$ and appetite suppression after administration of liraglutide was considered to be weak.

In dextran sulfate sodium colitis, liraglutide attenuates tight junction gene expression in the cecum. Given that LPS, a component of Gram-negative bacteria such as E. coli, is reported to reduce the levels of intestinal tight junction mRNA ${ }^{16,17}$, we examined the effects of liraglutide administration on intestinal barrier function. Under normal conditions, acute administration of liraglutide did not alter cecal occludin and TNF- $\alpha$ mRNA levels, but significantly increased cecal RegIII $\beta$ and IL-33 mRNA levels (Fig. 5A). In the dextran sulfate sodium (DSS) colitis model, the liraglutide group had significantly lower cecal occludin mRNA levels and significantly higher TNF- $\alpha$ mRNA levels compared with the control group, with no difference in body weight (Fig. 5B, Supplementary Fig. 3A). Reg III $\beta$ and IL-33 mRNA levels tended to be higher in the liraglutide group than in the control group (Fig. 5B). There was no difference between the two groups in the levels of other genes involved in intestinal barrier function (Supplementary Fig. 4). Because toll-like receptor-4 (TLR4) is a receptor for LPS, subsequent experiments were conducted using TLR4 knockout (TLR4KO) mice. Acute administration of liraglutide to TLR4KO mice during DSS colitis increased the expression of ClpB in cecal contents, consistent with the results in wild-type mice (Supplementary Fig. 3C). We found that the mRNA levels of cecal occludin and TNF- $\alpha$ were not different between the liraglutide group and the control group, with no difference in body weight (Fig. 5C, Supplementary Fig. 3B), suggesting that the liraglutide-induced reduction in occludin gene expression levels was LPS- and TLR4-dependent. In addition, cecal RegIII $\beta$ and IL-33 mRNA levels were signifi- 
A control
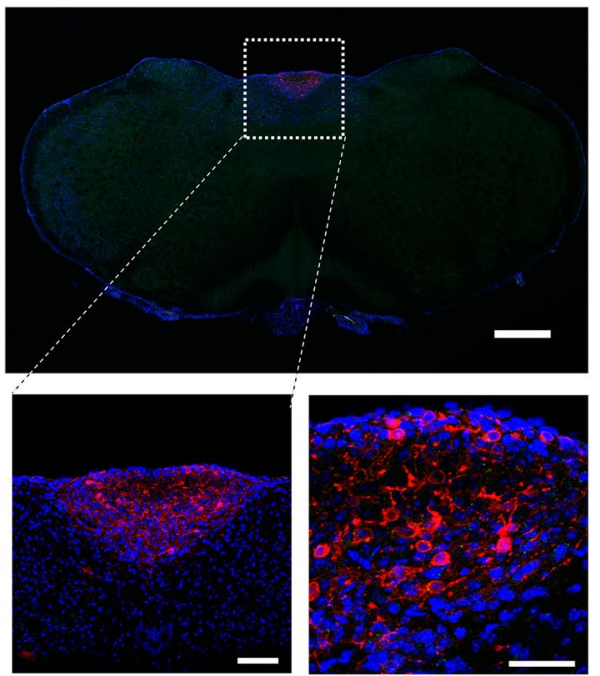

DAPI...Blue c-Fos...Green mCherry $\cdots$ Red liraglutide
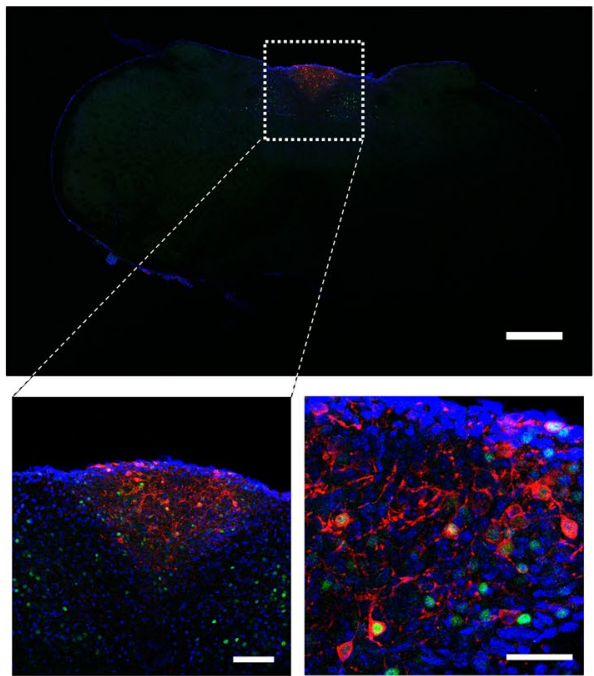

DAPI...Blue

c-Fos...Green

mCherry $\cdots$ Red

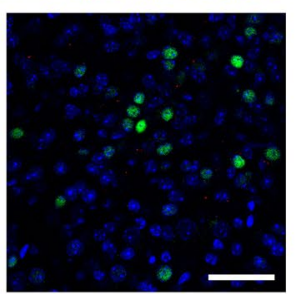

B
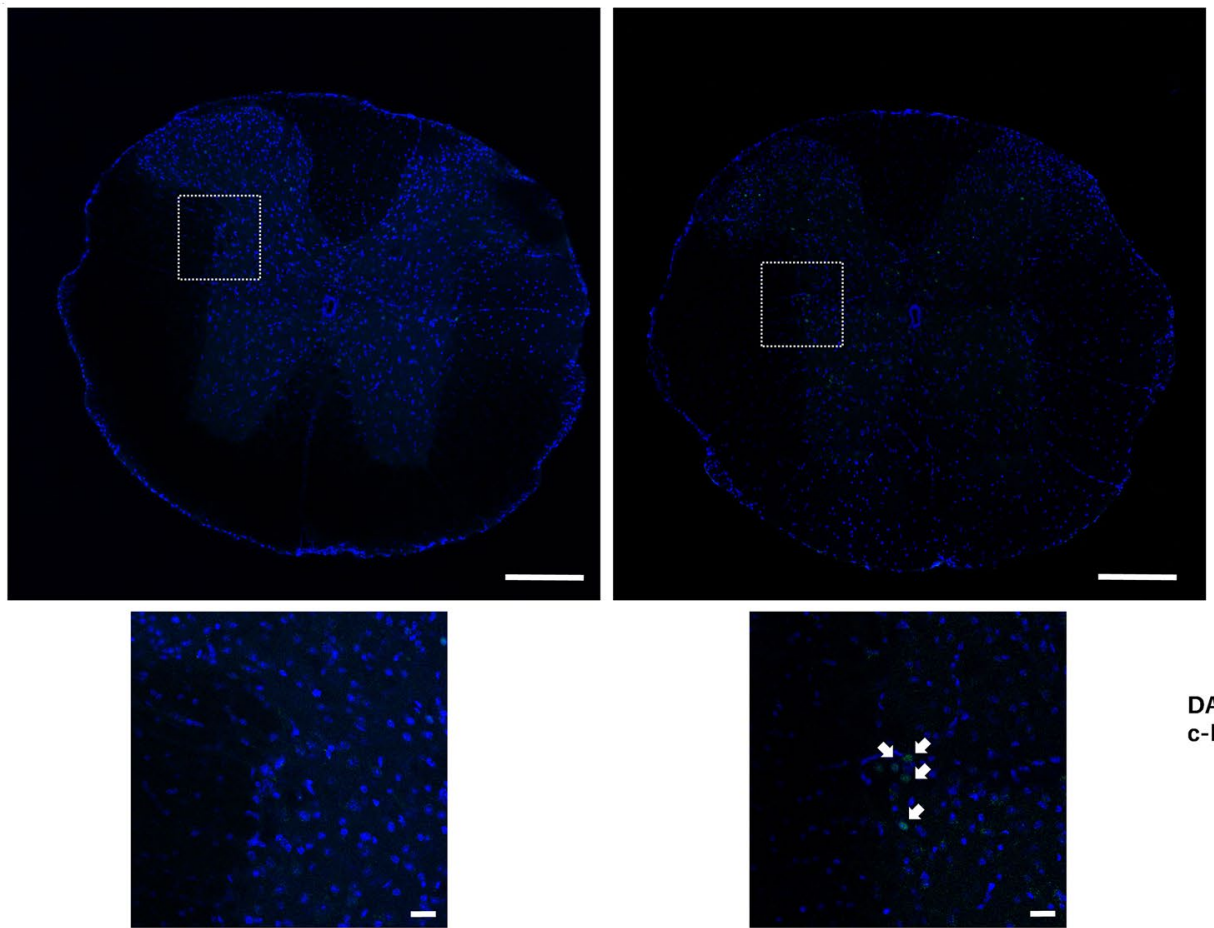

DAPI...B Blue

c-Fos...Green

Figure 4. Liraglutide enhances c-Fos staining, not only in the AP/NTS, but also in the IML. Representative image of immunohistochemistry for c-Fos in (A) the AP and NTS and (B) the IML with or without acute liraglutide administration. In (A), the top and middle left images are the original magnification, whereas the middle right and lower images are the original magnification $\times 40$. Scale bars: $500 \mu \mathrm{m}$ in the top image, $100 \mu \mathrm{m}$ in the middle left image, and $50 \mu \mathrm{m}$ in the middle right and lower images in (A). All images are the original magnification in (B). Scale bars: $200 \mu \mathrm{m}$ in the top image, $20 \mu \mathrm{m}$ in the lower image in (B). Arrows indicate c-Fos staining in (B). 

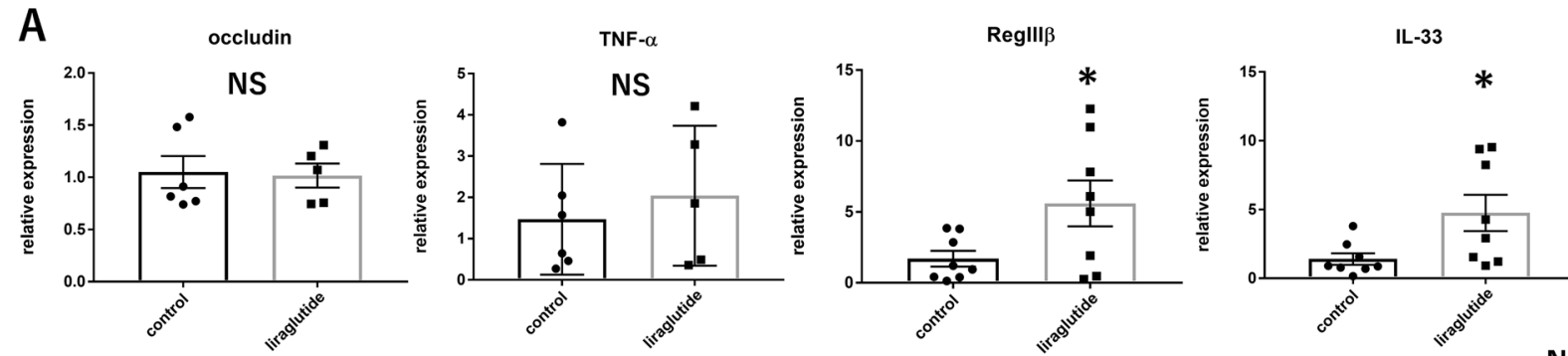

$\mathrm{N}=6-8,5-8$
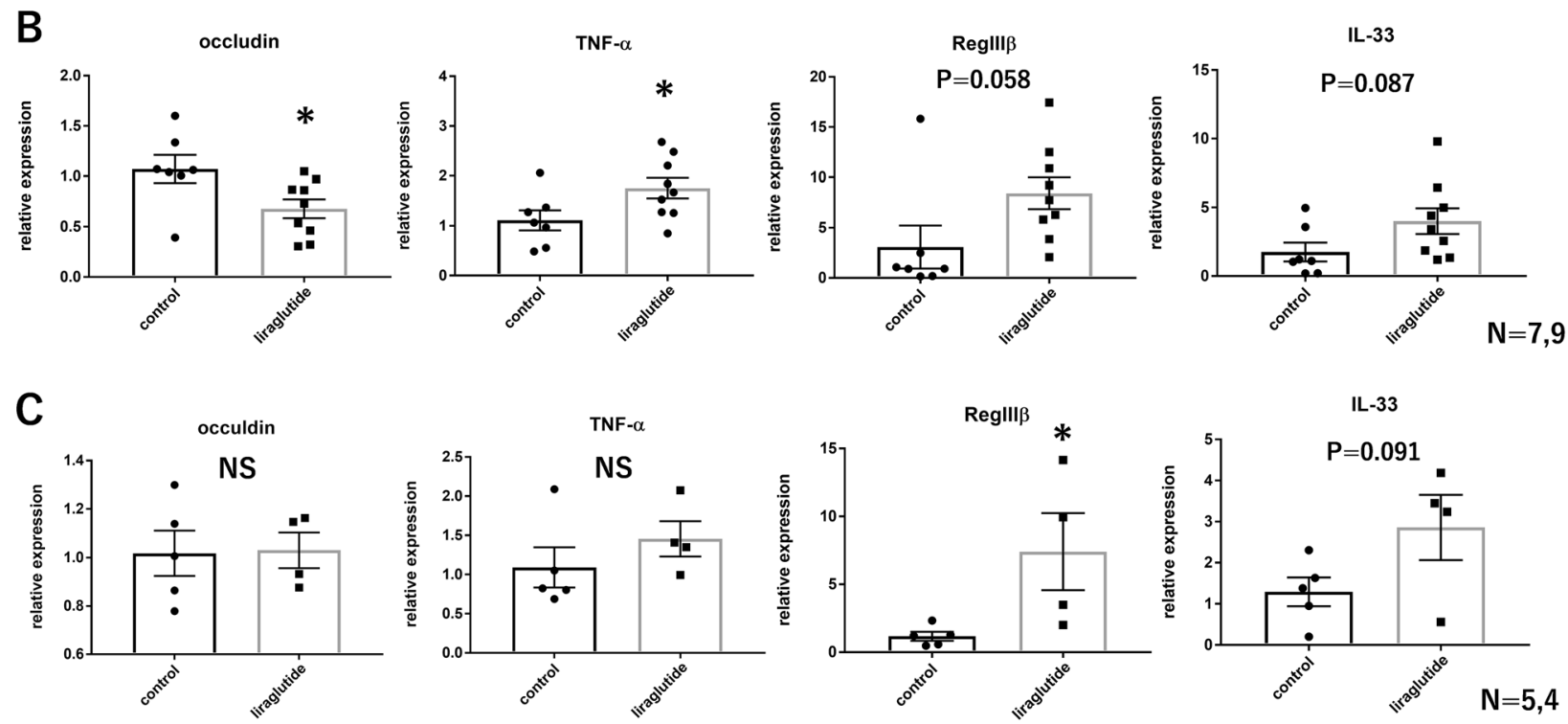

Figure 5. In DSS colitis, liraglutide attenuates tight junction gene expression in the cecum. Relative expression of cecal genes with or without acute liraglutide administration $(\mathbf{A})$ in wild-type mice (control, $\mathrm{n}=6-8$; liraglutide, $n=5-8$ ), $(\mathbf{B})$ in wild-type mice (control, $n=7$; liraglutide, $n=9$ ), and (C) in TLR4KO mice with DSS colitis (control, $\mathrm{n}=5$; liraglutide, $\mathrm{n}=4$ ). All values represent the mean \pm SEM. ${ }^{\star} P<0.05,{ }^{\star \star} P<0.01,{ }^{* \star \star} P<0.001$; NS, not significant by non-paired t-test (A-C). All figures were drawn using GraphPad Prism 7 (www.graphpad. com) and Microsoft's PowerPoint 2016 (www.microsoft.com).

cantly higher or tended to be higher than in the control group (Fig. 5C), suggesting that the increase in the levels of these genes was LPS- and TLR4-independent.

In DSS colitis, liraglutide promotes bacterial translocation. Cecal occludin mRNA levels showed a significant negative correlation with the relative expression of $\mathrm{ClpB}$ in cecal contents (Fig. 6A). To examine intestinal barrier function, we investigated the rate of bacterial translocation (BT) using spleen DNA. The positive rate was $100 \%$ (9 of 9) in the liraglutide group but just $14.3 \%$ ( 1 of 7 ) in the control group (Fig. 6B). In TLR4KO mice, the positive rates of BT were $100 \%$ (4 of 4 ) in the liraglutide group and $80 \%$ (4 of 5) in the control group (Fig. 6B). Cecal occludin mRNA levels were significantly lower in the BT-positive group than in the BT-negative group (Fig. 6C). Occludin mRNA levels were significantly lower in the BT-positive group of TLR4KO mice than in the BT-negative group of wild-type mice (Fig. 6C). Accordingly, acute administration of liraglutide may attenuate intestinal tight junction gene levels via an LPS- and TLR4-dependent mechanism and promote BT under stress conditions, such as those found in the colitis model.

\section{Discussion}

There are several reports on the effects of GLP-1RA on the gut microbiota in rodents ${ }^{26-28}$. However, the changes in the gut microbiota were not completely consistent among these studies. In addition, none of the studies discussed the changes in E. coli levels with GLP-1RA administration ${ }^{26-28}$. These reports were based on the study of gut microbiota in the feces after chronic administration of GLP-1RA. In the present work, liraglutide was acutely administered and DNA was extracted from cecal content. The gut microbiota in the cecum and feces are similar, but not necessarily the same. For example, more E. coli is detected in the cecum than in the feces ${ }^{36,37}$. Next, considering the duration of drug administration, GLP-1RA has a diminished effect after chronic administration, also known as tachyphylaxis, although the mechanism of tachyphylaxis is currently unclear. Liraglutide is a long-acting GLP-1RA that is more prone to tachyphylaxis related to delayed gastric emptying than short-acting GLP-1RAs such as exenatide ${ }^{38}$. Therefore, the changes in the gut microbiota after a single injection of GLP-1RA seem to reflect the original effects of GLP-1RA more clearly than the changes in the gut microbiota after chronic 
A total

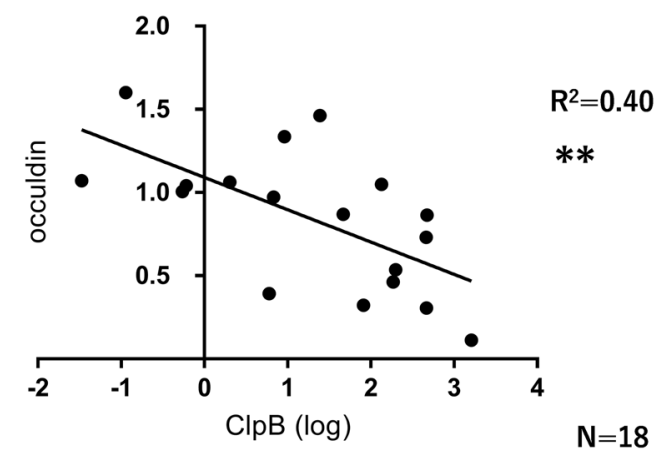

B

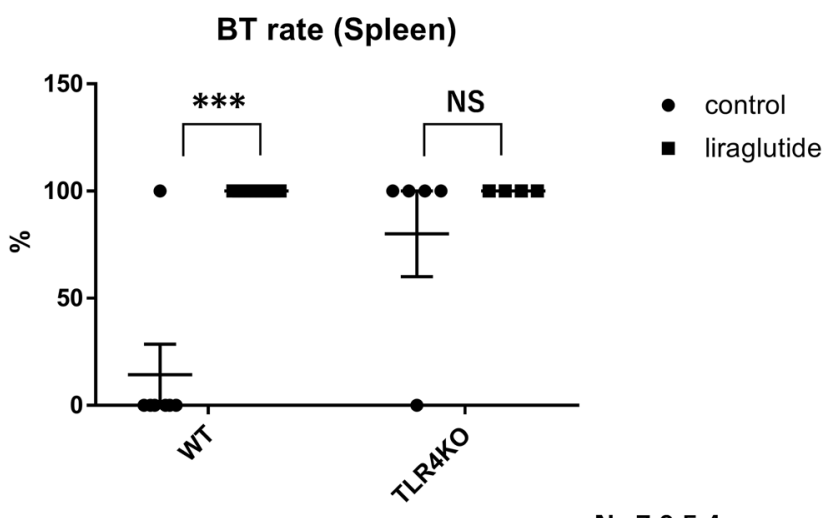

liraglutide

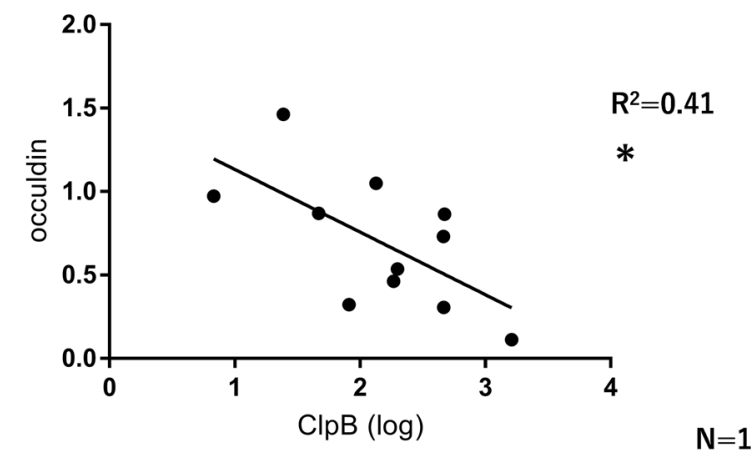

C

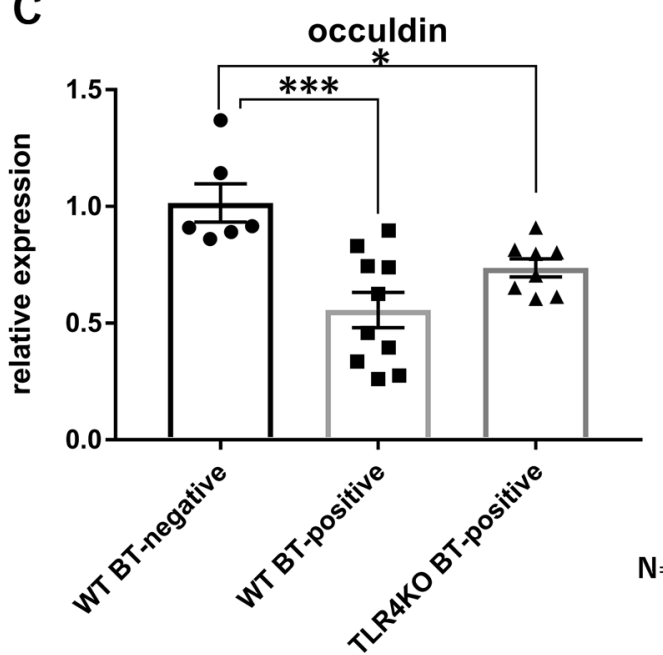

$\mathrm{N}=6,10,8$

Figure 6. In DSS colitis, liraglutide promotes bacterial translocation. (A) Correlation between the relative expression of ClpB in cecal contents and occludin in cecal tissue in mice with DSS colitis with or without acute liraglutide administration (total, $\mathrm{n}=18$; liraglutide, $\mathrm{n}=11$ ). (B) ClpB positive rate in the spleen under DSS colitis conditions in wild-type (WT) mice and TLR4KO mice with or without acute liraglutide administration (WT control, $n=7$; WT liraglutide, $n=9$; TLR4KO control, $n=5$; TLR4KO liraglutide, $n=4)$. (C) Cecal occludin gene expressions according to ClpB positivity (bacterial translocation [BT]) under DSS colitis conditions in wild-type (WT) mice and TLR4KO mice (WT BT-positive, $\mathrm{n}=6$; WT BT-negative, $\mathrm{n}=10$; TLR4KO BT-positive, $\mathrm{n}=8$ ). All values represent the mean \pm SEM. ${ }^{\star} P<0.05$, ${ }^{* *} P<0.01$, ${ }^{* *} P<0.001$; NS, not significant by linear regression analysis (A), two-way ANOVA with multiple comparison test (B), and one-way ANOVA with multiple comparison test $(\mathbf{C})$. The coefficient of determination is denoted as $\mathrm{R}^{2}$. All figures were drawn using GraphPad Prism 7 (www.graphpad.com) and Microsoft's PowerPoint 2016 (www.microsoft.com).

administration. The present study is significant in that it is the first to reveal a rapid increase in $E$. coli with acute administration of GLP-1RA.

We have shown that liraglutide administration increases NE levels in plasma and cecal contents. Asano et al. have already reported the presence of NE in the intestinal tract ${ }^{24}$. They showed that intestinal NE was reduced but still present in germ-free mice ${ }^{24}$. In other words, intestinal NE could be derived from two sources: the gut microbiota and the host. Here, we discovered that some of the NE in cecal contents is derived from the sympathetic nerves of the host because the liraglutide-induced NE increase was unaffected by adrenalectomy but suppressed by chemical sympathetic nerve blockade. Indeed, via the Ussing chamber, we confirmed that NE can pass into the intestinal lumen. Our results strongly suggest that GLP-1RA causes a surge of E. coli due to sympathetic nervous activation and subsequent increased NE release into the intestinal lumen.

Next, we must discuss GLP-RA and sympathetic nervous system activation. Two mechanisms of intestinal sympathetic nervous system activation by GLP-1RA must be considered: central nervous system-mediated effects and direct peripheral effects. The ENS also expresses GLP-1 receptors ${ }^{39}$, but the local effects of GLP-1 could not be proven because GLP-1RA was ineffective in our studies in Ussing chamber experiments. In the present study, subcutaneous administration of liraglutide led to activation in the NTS, AP, and IML. The result suggests that sympathetic nervous system activation by GLP-1RA is due to direct activation of AP without blood-brain barrier or indirect activation of NTS via vagal afferent nerves and AP. Indeed, we have reported that GLP-1 receptors are expressed in NTS and AP neurons and are depolarized by administration of GLP- $1^{30}$. Recently, it has been reported intraperitoneal administration of GLP-1RA activates mesenteric ganglia located periphery to the IML and inhibits intestinal motility ${ }^{40}$, which is consistent with our results. The present study is significant because it 
shows that the increase in intestinal NE caused by GLP-1RA is due to the involvement of central nervous system activation in addition to potential peripheral effects of GLP-1.

We need to also discuss the risks of an increase in E. coli. First, we must consider the adverse abdominal effects of GLP-1RA, which include nausea, abdominal distention, constipation, and diarrhea ${ }^{41,42}$. Nausea may be due to delayed gastric emptying, and abdominal distention and constipation may be due to delayed intestinal motility, but the reason for the diarrhea is unclear. Some E. coli strains can cause diarrhea. Therefore, the possibility that an increase in E. coli can cause diarrhea cannot be ruled out. We observed no diarrhea after acute administration of liraglutide. Investigation of the causal relationship between the increase in E. coli and diarrhea caused by GLP1RA use is an issue for future study. Secondly, we examined the BT of E. coli. Under DSS colitis conditions, we observed that liraglutide administration attenuated occludin mRNA levels and increased TNF- $\alpha$ mRNA levels in the cecum. Occludin gene expression was negatively correlated with ClpB expression in cecal contents, suggesting that occludin may have been affected by E. coli. There is no report that GLP-1RA increases BT, but there are reports that GLP-1 levels are high in critically ill patients and those with sepsis ${ }^{43,44}$. Furthermore, elevated levels of GLP-1 have been reported in patients with IBD ${ }^{45,46}$. In addition, the severity of the condition has been associated with an increase in E. coli in a murine IBD model ${ }^{11}$. However, there has been no concurrent investigation of the increase in GLP-1, E. coli, and IBD severity, and a future study in humans should be conducted.

Additional important aspects are the benefits of increased levels of $E$. coli and the new significance of GLP- 1 . To begin with, GLP-1 is secreted by L cells in the lower intestine, and its secretory stimuli include nutrients, the gut microbiota itself, and metabolites of the gut microbiota, such as short-chain fatty acids ${ }^{47,48}$. These stimuli are foreign substances and the purpose of the sympathetic nervous system activation may be to protect the host from foreign substances. Indeed, activation of the sympathetic nervous system activates immune cells, which have also been reported to be potentially beneficial to the host ${ }^{49}$. Thus, are changes in the gut bacterium itself beneficial to the host? Reports that increased postprandial E. coli suppresses postprandial blood glucose or appetite in the host may be the result of interactions between the host and the gut microbiota ${ }^{14,15}$. In other words, the gut microbiota and the host may have evolved with each other to produce mutually beneficial outcomes. In the present study, the effect of the increased ClpB on appetite is not clear, and inhibition of glycogenesis by increased LPS has not been examined. In terms of the host-bacterial symbiosis, changes in the gut microbiota may benefit the host and should be examined in detail in the future.

The limitations of our study are as follows. First, this study was limited to a single dose and fasting conditions because we excluded the effect of diet and examined the direct effect of GLP-1RA. Another approach would have been to conduct a pair-feeding study, but this was not done because it was not possible to make all feeding conditions exactly the same. In addition, it is difficult to apply the results of this study to humans because it is not common to administer GLP-1RA under fasting conditions in humans. Secondly, this study was limited to changes in E. coli. Although metagenomic analysis using Next-Generation Sequencing (NGS) is useful for estimating the overall view of the gut microbiota, it is less sensitive than qPCR at the species or strain level ${ }^{50}$. It has been reported that the data obtained by NGS and qPCR are correlated, so the results of this study will not be changed by $\mathrm{NGS}^{51}$. However, the analysis of the gut microbiota using NGS after a single administration of GLP-1RA has not been studied, and this is a subject for further study. Third, we may not be controlling the TLR4 ligands, since there are many TLR4 ligands other than LPS. For example, GLP-1RA has been reported to alter free fatty acid and LDL cholesterol levels which are TLR4 ligands ${ }^{52,53}$. Therefore, it is necessary to consider the possibility that these changes affected the results. Finally, with regard to BT, the viability of the bacteria is unclear, and the translocation of bacteria other than E. coli has not been examined. For the former, BT has been defined as the migration of bacteria or bacterial products from intestinal contents to extra-intestinal organs ${ }^{54}$. In several previous papers, BT has been confirmed by using PCR, therefore we also confirmed the BT of $E$. coli by using $\mathrm{PCR}^{55-57}$. However, the viability of the bacteria is unknown, and this is a subject for further study. In the latter, E. coli has been reported to be one of the easiest bacteria to translocate ${ }^{58}$. It has also been reported that certain E. coli are suitable for determining BT ${ }^{59}$. Therefore, we selected E. coli as the indicator of BT. BT of other bacteria is also a future issue.

In conclusion, we show for the first time that one mechanism for the GLP-1RA-induced increase in intestinal E. coli is related to sympathetic nervous system activation and the subsequent release of NE into the intestinal lumen (Fig. 7). The increase in E. coli may help to promote BT by attenuating intestinal tight junction gene levels under stress conditions (Fig. 7). Finally, the benefits of increased levels of E. coli are a subject for further study.

\begin{abstract}
Materials and methods
Mouse experiments. C57BL/6J mice were used at 8-16 weeks of age. Mice were housed in a controlled environment under a 12-h light/dark cycle and with ad libitum access to standard rodent chow and water. Animal experiments were carried out in accordance with the animal welfare guidelines of Akita University and the ARRIVE (Animal Research: Reporting of In Vivo Experiments) guidelines. All procedures were approved by the committee on animal experimentation of Akita University. We housed each mouse individually in a cage. Mice were subcutaneously injected with liraglutide ( $200 \mu \mathrm{g} / \mathrm{kg}$ body weight) (NOVO Nordisk, Bagsvaerd, Denmark) or saline. The relative ClpB expression levels at 2, 6, and $16 \mathrm{~h}$ after liraglutide administration were examined (Supplementary Fig. 5), and based on the results, "16 h" was adopted for this study. After overnight fasting for $16 \mathrm{~h}$, we collected blood from the inferior vena cava of mice anesthetized with isoflurane. The contents of the cecum were collected. The cecal tissue was immediately frozen with dry ice and stored at $-80{ }^{\circ} \mathrm{C}$. The same experiment was also performed in the non-fasting condition.
\end{abstract}

Chemical sympathectomy study. Intraperitoneal administration of an a2-adrenoreceptor agonist (medetomidine $600 \mu \mathrm{g} / \mathrm{kg}$ body weight; Nippon Zenyaku Kogyo Co., Ltd., Tokyo, Japan) was used for chemical 


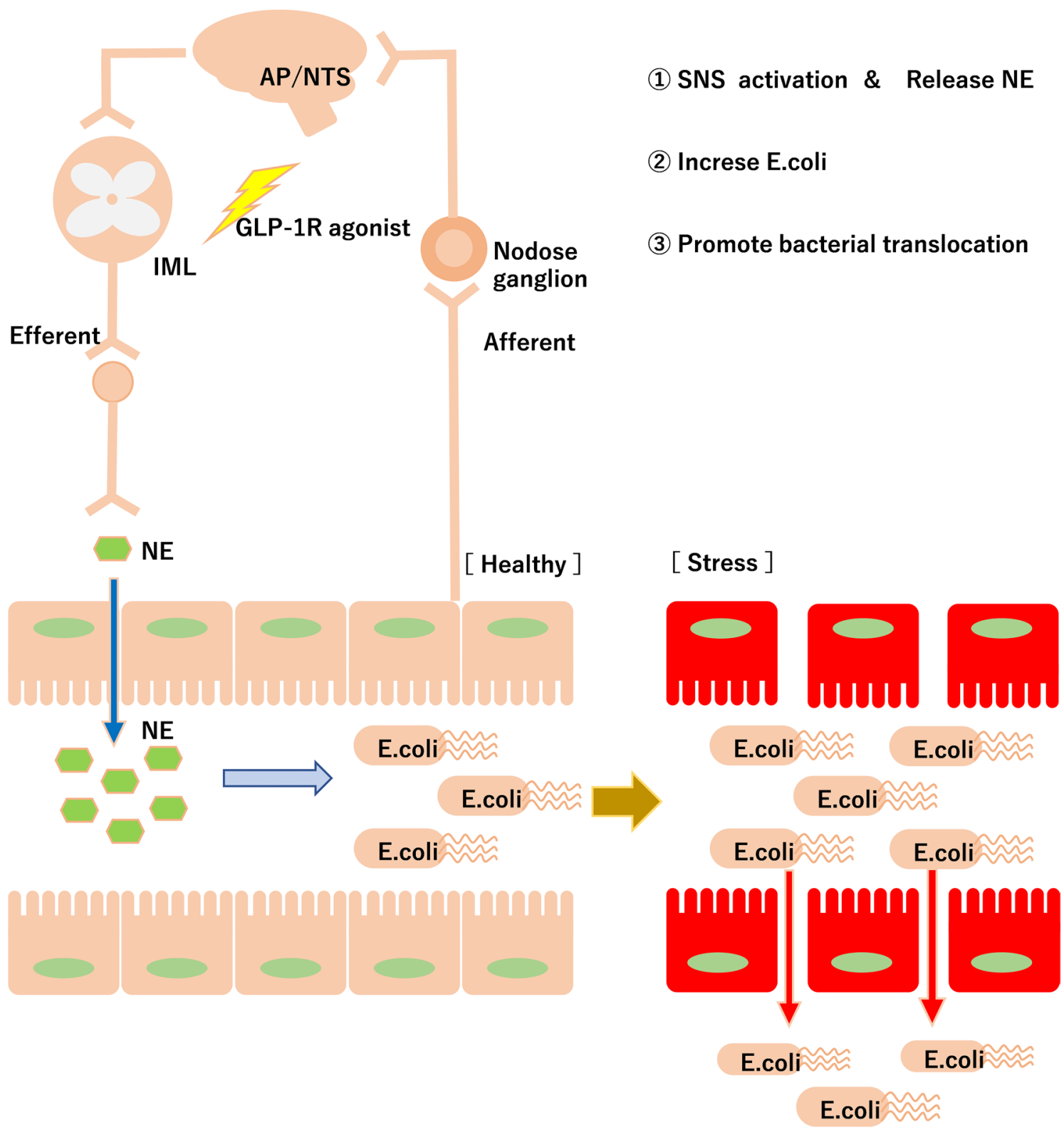

Figure 7. Schematic of this experiment. Acute administration of liraglutide causes these three phenomena: (1) sympathetic nervous system (SNS) activation and release of norepinephrine to the intestinal lumen, (2) increased levels of $E$. coli in cecal contents, and (3) promotion of bacterial translocation under stress conditions, such as colitis. This image was drawn using Microsoft's PowerPoint 2016 (www.microsoft.com).

sympathectomy. The control group received the same amount of intraperitoneal saline. Subsequently, dissections were performed under the same conditions as above.

Adrenalectomy study. A combination anesthetic was prepared with medetomidine $(0.3 \mathrm{mg} / \mathrm{kg}$ body weight; Nippon Zenyaku Kogyo Co., Ltd.), midazolam (4 mg/kg body weight; Astellas Pharma Inc., Tokyo, Japan), and butorphanol (5 mg/kg body weight; Meiji Seika Pharma Co., Ltd., Tokyo, Japan). The median back skin and the back muscles were incised longitudinally at two locations on the left and right sides to expose the adrenal glands and were resected with scissors. After completion of the operation, $1 \mathrm{ml}$ of warmed saline and dexamethasone ( $1 \mathrm{mg} / \mathrm{kg}$ body weight; FUJIFILM Wako Pure Chemical Corporation, Osaka, Japan) were intraperitoneally administered, and atipamezole $(2.5 \mathrm{mg} / \mathrm{kg}$ body weight; Nippon Zenyaku Kogyo Co.) was also intraperitoneally administered for reversal. Thereafter, $0.9 \%$ saline was supplied for drinking. Four weeks later, liraglutide or saline was injected subcutaneously and dissection was performed as above.

Antibiotics study. Antibiotics (ampicillin $1 \mathrm{~g} / \mathrm{L}$, neomycin $1 \mathrm{~g} / \mathrm{L}$, metronidazole $1 \mathrm{~g} / \mathrm{L}$; FUJIFILM Wako Pure Chemical Corporation) were administered in drinking water to depress gut microbiota. Two weeks after initiation of the antibiotics, we administered a single subcutaneous injection of liraglutide or saline to the mice. 
After the mice were fasted for $16 \mathrm{~h}$, food intake was measured 1, 3, 6, and $24 \mathrm{~h}$ later. Mice that drank water without antibiotics were used as controls to perform experiments in the same way.

Fecal microbiota transplantation study. Donor mice were subcutaneously injected with liraglutide or saline under fasting conditions and cecal contents were collected the following morning under isoflurane anesthesia. With $0.25 \mathrm{~g}$ of cecal contents per $1 \mathrm{ml}$ of sterilized water, the prepared liquid was passed through a $70-\mu \mathrm{m}$ cell strainer. The recipient mice were fed water with antibiotics for 2 weeks and changed to normal water 2 days before the fecal microbiota transplantation (FMT) was performed. After the recipient mice were fasted overnight for $16 \mathrm{~h}$, the prepared liquid was administered orally and food intake was measured after 1, 3, 6, and $24 \mathrm{~h}$.

Dextran sulfate sodium colitis study. Wild-type mice (8-12 weeks of age) were allowed ad libitum access to drinking water containing $1.5 \%-2 \%$ dextran sulfate sodium (DSS, MW =36,000-50,000; MP Biomedicals, Solon, $\mathrm{OH}$ ) for 8-12 days (4-5 animals/cage). In addition, toll-like receptor-4 knockout (TLR4KO) mice (10-12 weeks of age; Oriental Bio Service, Inc., Kyoto, Japan) were allowed ad libitum access to drinking water containing 1.5\% DSS for 8 days. Body weight was measured every 2 to 3 days. One day before dissection, body weight measured and the DSS-containing water was changed to normal water. After administration of liraglutide or saline, the mice were fasted for $16 \mathrm{~h}$ and the dissection was performed as above.

Ussing chamber study. Nonfasted mice were dissected under isoflurane anesthesia, and the cecal tissue was removed and washed well with Krebs Ringer solution (117 mM NaCl, $5.9 \mathrm{mM} \mathrm{KCl}, 2.5 \mathrm{mM} \mathrm{CaCl}, 1.2 \mathrm{mM}$ $\mathrm{MgCl}_{2}, 24.8 \mathrm{mM} \mathrm{NaHCO}_{3}, 1.2 \mathrm{mM} \mathrm{NaH}_{2} \mathrm{PO}_{4}$, and $11.1 \mathrm{mM}$ glucose). The opened cecal tissue was mounted to act as a 19.6- $\mathrm{mm}^{2}$ diaphragm between the two halves of a customized Ussing chamber. The mucosal side of the chamber had a volume of $1 \mathrm{ml}$ and the serosal side had a volume of $500 \mu$ l. The chambers were filled with Krebs Ringer solution with bubbling $95 \% \mathrm{O}_{2}-5 \% \mathrm{CO}_{2}$. In the chemical stimulation assay, $\mathrm{KCl}(60 \mathrm{mM})$, carbachol (100 $\mu \mathrm{M}$; Sigma-Aldrich, St. Louis, MO), exendin-4 (100 nM; Sigma-Aldrich), and capsaicin (10 $\mu$ M; SigmaAldrich) were added to the serosal side for $15 \mathrm{~min}$. Then, $50 \mu \mathrm{l}$ of samples were taken from the mucosal side $5 \mathrm{~min}$ before and $15 \mathrm{~min}$ after drug administration. The NE concentration in the sample was measured using the Noradrenaline Research ELISA kit (BA-E-5200; LDN, Nordhorn, Germany).

c-Fos staining. We intraperitoneally injected the adeno-associated virus (AAV) series (AAV-CAG-GFP, Addgene, MA, USA) into neonatal mice and found that the AP region was labeled with AAV-9. Therefore, in the c-Fos staining of the AP and NTS, we used mice injected with AAV-9-CaMKIIa-hChR2(E123T/T159C)mCherry $(3 \times 10 \mathrm{e} 13,2 \mu \mathrm{l})$ (Penn Vector Core, Philadelphia, PA) during the neonatal period. After $4 \mathrm{~h}$ of fasting, 8-12-week-old wild-type mice were subcutaneously injected with liraglutide $(400 \mu \mathrm{g} / \mathrm{kg}$ body weight $)$ or saline and, $2 \mathrm{~h}$ later, were dissected under inhalation anesthesia with isoflurane. The mice were intracardially perfused with phosphate-buffered saline (PBS) followed by cold $4 \%$ paraformaldehyde (PFA) in PBS. Immediately after fixation, the brain and spinal cord were manually removed. They were embedded in agarose, and a specimen with a cross-section thickness of $80 \mu \mathrm{m}$ was prepared. After three washes with PBS, the sections were pre-incubated in blocking solution (5\% serum albumin, $2 \%$ normal goat serum, and $0.3 \%$ Triton X-100 in PBS) for $20 \mathrm{~min}$ at room temperature, then incubated with an anti-c-Fos rabbit antibody (\#sc-52, 1:2000; Santa Cruz Biotechnology, Santa Cruz, CA) and an anti-mCherry rat antibody (\#M11217, 1:1000; Life Sciences, Madison, WI) in blocking solution for $16 \mathrm{~h}$ at $4{ }^{\circ} \mathrm{C}$. After three washes with PBS, the sections were incubated with goat anti-rabbit IgG antibody coupled with Alexa Fluor 488 (1: 500; Invitrogen, Carlsbad, CA) and donkey anti-rat IgG antibody coupled with Cy3 (1: 250; Jackson ImmunoResearch Inc., West Grove, PA) in blocking solution for $90 \mathrm{~min}$ at room temperature. After three washes with PBS, the sections were coverslipped using Vectashield mounting medium with DAPI (Vector, Burlingame, CA). Fluorescent images were obtained using confocal laser microscopy (LSM510; Carl Zeiss, Jena, Germany). For spinal cord staining, we used mice not injected with AAV-9.

Gene expression analysis. Total RNA from cecal tissue was isolated using the RNeasy Mini kit (Qiagen, Valencia, CA). cDNA was synthesized using the PrimeScript 1st strand cDNA Synthesis Kit (Takara Bio, Shiga, Japan). Quantitative reverse transcriptase-PCR was performed using the SYBR Green I Kit (Roche, Mannheim, Germany). We extracted DNA from cecal contents and the spleen using the DNA Stool Mini kit (Qiagen). Quantitative PCR was performed using the SYBR Green or TaqMan methods. The primers used are summarized in Supplementary Table 6 . The $16 \mathrm{~S}$ rRNA gene was used as an internal control in the analysis of the gut bacterium, whereas the $18 \mathrm{~S}$ rRNA gene was used in the analysis of cecal genes. The comparative $\Delta \mathrm{Ct}$ method was used for both analyses. Analysis of splenic ClpB was performed by quantitative PCR using $100 \mathrm{ng}$ DNA as template. When the amplification curve rose within 40 cycles of the PCR reaction, it was considered positive.

Norepinephrine measurement. Norepinephrine (NE) levels in plasma and cecal contents were measured using a Noradrenaline Research ELISA kit. We conducted the experiments according to the manufacturer's protocol. Briefly, after centrifugation at $13,000 \times \mathrm{g}$ for $10 \mathrm{~min}, 10 \mu \mathrm{l}$ of plasma was used. The contents of the cecum were mixed with sterilized water at a rate of $0.25 \mathrm{~g}$ per $1 \mathrm{ml}$ and centrifuged at $13,000 \times g$ for $15 \mathrm{~min}$, and then $100 \mu \mathrm{l}$ of supernatant was used. The cross reactivity was $0.14 \%$ for adrenaline and $0.2 \%$ for dopamine. 
Statistical analysis. Non-paired t-test, one-way ANOVA, two-way ANOVA, and linear regression analysis were performed with GraphPad Prism 7 (GraphPad, San Diego, CA). Data are shown as the mean \pm SEM. Statistical significance was set at $P<0.05$.

\section{Data availability}

Data are available upon relevant request to the corresponding author.

Received: 14 October 2020; Accepted: 13 April 2021

Published online: 28 April 2021

\section{References}

1. Sharon, G. et al. Specialized metabolites from the microbiome in health and disease. Cell Metab. 20, 719-730. https://doi.org/10. 1016/j.cmet.2014.10.016 (2014).

2. Zhang, X. et al. Human gut microbiota changes reveal the progression of glucose intolerance. PLoS ONE 8, e71108. https://doi. org/10.1371/journal.pone.0071108 (2013).

3. Kostic, A. D. et al. The dynamics of the human infant gut microbiome in development and in progression toward type 1 diabetes. Cell Host Microbe 17, 260-273. https://doi.org/10.1016/j.chom.2015.01.001 (2015).

4. Zhao, G. et al. Intestinal virome changes precede autoimmunity in type I diabetes-susceptible children. Proc. Natl. Acad. Sci. U. S. A. 114, E6166-E6175. https://doi.org/10.1073/pnas.1706359114 (2017).

5. Shimokawa, C. et al. CD8 regulatory T cells are critical in prevention of autoimmune-mediated diabetes. Nat. Commun. 11, 1922. https://doi.org/10.1038/s41467-020-15857-x (2020).

6. Wu, H. et al. Metformin alters the gut microbiome of individuals with treatment-naive type 2 diabetes, contributing to the therapeutic effects of the drug. Nat. Med. 23, 850-858. https://doi.org/10.1038/nm.4345 (2017).

7. Zhang, X. et al. Effects of acarbose on the gut microbiota of prediabetic patients: a randomized, double-blind, controlled crossover trial. Diabetes Ther. 8, 293-307. https://doi.org/10.1007/s13300-017-0226-y (2017).

8. Bai, J., Zhu, Y. \& Dong, Y. Response of gut microbiota and inflammatory status to bitter melon (Momordica charantia L.) in high fat diet induced obese rats. J. Ethnopharmacol. 194, 717-726. https://doi.org/10.1016/j.jep.2016.10.043 (2016).

9. Stromberg, Z. R. et al. Pathogenic and non-pathogenic. Dis. Model. Mech. https://doi.org/10.1242/dmm.035063 (2018).

10. Nagao-Kitamoto, H. \& Kamada, N. Host-microbial cross-talk in inflammatory bowel disease. Immune Netw. 17, 1-12. https://doi. org/10.4110/in.2017.17.1.1 (2017).

11. Jia, H. et al. Eggshell membrane powder ameliorates intestinal inflammation by facilitating the restitution of epithelial injury and alleviating microbial dysbiosis. Sci. Rep. 7, 43993. https://doi.org/10.1038/srep43993 (2017).

12. Escribano-Vazquez, U. et al. The commensal Escherichia coli CEC15 reinforces intestinal defences in gnotobiotic mice and is protective in a chronic colitis mouse model. Sci. Rep. 9, 11431. https://doi.org/10.1038/s41598-019-47611-9 (2019).

13. Christofi, T., Panayidou, S., Dieronitou, I., Michael, C. \& Apidianakis, Y. Metabolic output defines Escherichia coli as a healthpromoting microbe against intestinal Pseudomonas aeruginosa. Sci. Rep. 9, 14463. https://doi.org/10.1038/s41598-019-51058-3 (2019).

14. Breton, J. et al. Gut commensal E. coli proteins activate host satiety pathways following nutrient-induced bacterial growth. Cell Metab. 23, 324-334. https://doi.org/10.1016/j.cmet.2015.10.017 (2016).

15. Toda, G. et al. Insulin- and lipopolysaccharide-mediated signaling in adipose tissue macrophages regulates postprandial glycemia through Akt-mTOR activation. Mol. Cell 79, 43-53.e44. https://doi.org/10.1016/j.molcel.2020.04.033 (2020).

16. Guo, S., Al-Sadi, R., Said, H. M. \& Ma, T. Y. Lipopolysaccharide causes an increase in intestinal tight junction permeability in vitro and in vivo by inducing enterocyte membrane expression and localization of TLR-4 and CD14. Am. J. Pathol. 182, 375-387. https:// doi.org/10.1016/j.ajpath.2012.10.014 (2013).

17. Qin, L. H., Huang, W., Mo, X. A., Chen, Y. L. \& Wu, X. H. LPS induces occludin dysregulation in cerebral microvascular endothelial cells via MAPK signaling and augmenting MMP-2 levels. Oxid. Med. Cell Longev. 2015, 120641. https://doi.org/10.1155/2015/ 120641 (2015).

18. Tetz, G., Brown, S. M., Hao, Y. \& Tetz, V. Type 1 diabetes: an association between autoimmunity, the dynamics of gut amyloidproducing E. coli and their phages. Sci. Rep. 9, 9685. https://doi.org/10.1038/s41598-019-46087-x (2019).

19. Tursi, S. A. et al. Bacterial amyloid curli acts as a carrier for DNA to elicit an autoimmune response via TLR2 and TLR9. PLoS Pathog. 13, e1006315. https://doi.org/10.1371/journal.ppat.1006315 (2017).

20. Burton, C. L. et al. The growth response of Escherichia coli to neurotransmitters and related catecholamine drugs requires a functional enterobactin biosynthesis and uptake system. Infect. Immun. 70, 5913-5923. https://doi.org/10.1128/iai.70.11.5913-5923. 2002 (2002).

21. Santiago-Rodriguez, T. M. \& Hollister, E. B. Human virome and disease: high-throughput sequencing for virus discovery, identification of phage-bacteria dysbiosis and development of therapeutic approaches with emphasis on the human gut. Viruses https:// doi.org/10.3390/v11070656 (2019).

22. Tetz, G. \& Tetz, V. Bacteriophages as new human viral pathogens. Microorganisms https://doi.org/10.3390/microorganisms6020054 (2018).

23. De Paepe, M., Leclerc, M., Tinsley, C. R. \& Petit, M. A. Bacteriophages: an underestimated role in human and animal health?. Front. Cell Infect. Microbiol. 4, 39. https://doi.org/10.3389/fcimb.2014.00039 (2014).

24. Asano, Y. et al. Critical role of gut microbiota in the production of biologically active, free catecholamines in the gut lumen of mice. Am. J. Physiol. Gastrointest. Liver Physiol. 303, G1288-1295. https://doi.org/10.1152/ajpgi.00341.2012 (2012).

25. Seino, Y. \& Yabe, D. Glucose-dependent insulinotropic polypeptide and glucagon-like peptide-1: incretin actions beyond the pancreas. J. Diabetes Investig. 4, 108-130. https://doi.org/10.1111/jdi.12065 (2013).

26. Wang, L., Li, P., Tang, Z., Yan, X. \& Feng, B. Structural modulation of the gut microbiota and the relationship with body weight: compared evaluation of liraglutide and saxagliptin treatment. Sci. Rep. 6, 33251. https://doi.org/10.1038/srep33251 (2016).

27. Zhang, Q. et al. Featured article: Structure moderation of gut microbiota in liraglutide-treated diabetic male rats. Exp. Biol. Med. (Maywood) 243, 34-44. https://doi.org/10.1177/1535370217743765 (2018).

28. Zhao, L. et al. A glucagon-like peptide-1 receptor agonist lowers weight by modulating the structure of gut microbiota. Front. Endocrinol. (Lausanne) 9, 233. https://doi.org/10.3389/fendo.2018.00233 (2018).

29. Yamamoto, H. et al. Glucagon-like peptide-1 receptor stimulation increases blood pressure and heart rate and activates autonomic regulatory neurons. J. Clin. Invest. 110, 43-52. https://doi.org/10.1172/JCI15595 (2002).

30. Kawatani, M. \& Yamada, Y. Glucagon-like peptide-1 (GLP-1) action in the mouse area postrema neurons. Peptides 107, 68-74. https://doi.org/10.1016/j.peptides.2018.07.010 (2018).

31. Baggio, L. L. et al. The autonomic nervous system and cardiac GLP-1 receptors control heart rate in mice. Mol. Metab. 6, 1339-1349. https://doi.org/10.1016/j.molmet.2017.08.010 (2017). 
32. Baggio, L. L. et al. GLP-1 receptor expression within the human heart. Endocrinology 159, 1570-1584. https://doi.org/10.1210/en. 2018-00004 (2018).

33. Amato, A. et al. Peripheral motor action of glucagon-like peptide-1 through enteric neuronal receptors. Neurogastroenterol. Motil. 22, 664-e203. https://doi.org/10.1111/j.1365-2982.2010.01476.x (2010).

34. Kawatani, M., Itoi, K., Talukder, A. H., Uchida, K. \& Sakimura, K. Cholinergic modulation of CRH and non-CRH neurons in Barrington's nucleus of the mouse. J. Neurophysiol. 124, 443-457. https://doi.org/10.1152/jn.00342.2019 (2020).

35. Tennoune, N. et al. Bacterial ClpB heat-shock protein, an antigen-mimetic of the anorexigenic peptide $\alpha-\mathrm{MSH}$, at the origin of eating disorders. Transl. Psychiatry 4, e458. https://doi.org/10.1038/tp.2014.98 (2014).

36. He, M. et al. Evaluating the contribution of gut microbiota to the variation of porcine fatness with the cecum and fecal samples. Front. Microbiol. 7, 2108. https://doi.org/10.3389/fmicb.2016.02108 (2016).

37. Kasai, C. et al. Comparison of the gut microbiota composition between obese and non-obese individuals in a Japanese population, as analyzed by terminal restriction fragment length polymorphism and next-generation sequencing. BMC Gastroenterol. 15, 100. https://doi.org/10.1186/s12876-015-0330-2 (2015).

38. Uccellatore, A., Genovese, S., Dicembrini, I., Mannucci, E. \& Ceriello, A. Comparison review of short-acting and long-acting glucagon-like peptide-1 receptor agonists. Diabetes Ther. 6, 239-256. https://doi.org/10.1007/s13300-015-0127-x (2015).

39. Grasset, E. et al. A specific gut microbiota dysbiosis of type 2 diabetic mice induces GLP-1 resistance through an enteric NOdependent and gut-brain axis mechanism. Cell Metab. 26, 278. https://doi.org/10.1016/j.cmet.2017.06.003 (2017).

40. Muller, P. A. et al. Microbiota modulate sympathetic neurons via a gut-brain circuit. Nature 583, 441-446. https://doi.org/10.1038/ s41586-020-2474-7 (2020).

41. Bettge, K., Kahle, M., Abd El Aziz, M. S., Meier, J. J. \& Nauck, M. A. Occurrence of nausea, vomiting and diarrhoea reported as adverse events in clinical trials studying glucagon-like peptide-1 receptor agonists: a systematic analysis of published clinical trials. Diabetes Obes. Metab. 19, 336-347. https://doi.org/10.1111/dom.12824 (2017).

42. Horowitz, M., Aroda, V. R., Han, J., Hardy, E. \& Rayner, C. K. Upper and/or lower gastrointestinal adverse events with glucagonlike peptide-1 receptor agonists: Incidence and consequences. Diabetes Obes. Metab. 19, 672-681. https://doi.org/10.1111/dom. 12872 (2017).

43. Kahles, F. et al. GLP-1 secretion is increased by inflammatory stimuli in an IL-6-dependent manner, leading to hyperinsulinemia and blood glucose lowering. Diabetes 63, 3221-3229. https://doi.org/10.2337/db14-0100 (2014).

44. Lebherz, C. et al. GLP-1 levels predict mortality in patients with critical illness as well as end-stage renal disease. Am. J. Med. 130, 833-841.e833. https://doi.org/10.1016/j.amjmed.2017.03.010 (2017).

45. Keller, J. et al. Gastric emptying and disease activity in inflammatory bowel disease. Eur. J. Clin. Invest. 45, 1234-1242. https://doi. org/10.1111/eci.12542 (2015).

46. Keller, J., Beglinger, C., Holst, J. J., Andresen, V. \& Layer, P. Mechanisms of gastric emptying disturbances in chronic and acute inflammation of the distal gastrointestinal tract. Am. J. Physiol. Gastrointest. Liver Physiol. 297, G861-868. https://doi.org/10.1152/ ajpgi.00145.2009 (2009).

47. Lebrun, L. J. et al. Enteroendocrine L cells sense LPS after gut barrier injury to enhance GLP-1 secretion. Cell Rep. 21, 1160-1168. https://doi.org/10.1016/j.celrep.2017.10.008 (2017).

48. Greiner, T. U. \& Bäckhed, F. Microbial regulation of GLP-1 and L-cell biology. Mol. Metab. 5, 753-758. https://doi.org/10.1016/j. molmet.2016.05.012 (2016).

49. Jänig, W. Sympathetic nervous system and inflammation: a conceptual view. Auton. Neurosci. 182, 4-14. https://doi.org/10.1016/j. autneu.2014.01.004 (2014).

50. Kroneis, T., Jonasson, E., Andersson, D., Dolatabadi, S. \& Ståhlberg, A. Global preamplification simplifies targeted mRNA quantification. Sci. Rep. 7, 45219. https://doi.org/10.1038/srep45219 (2017)

51. Wu, A. R. et al. Quantitative assessment of single-cell RNA-sequencing methods. Nat. Methods 11, 41-46. https://doi.org/10.1038/ nmeth.2694 (2014).

52. Chen, X. M. et al. Liraglutide suppresses non-esterified free fatty acids and soluble vascular cell adhesion molecule-1 compared with metformin in patients with recent-onset type 2 diabetes. Cardiovasc. Diabetol. 17, 53. https://doi.org/10.1186/s12933-0180701-4 (2018).

53. Wu, Y. R. et al. Liraglutide improves lipid metabolism by enhancing cholesterol efflux associated with ABCA1 and ERK1/2 pathway. Cardiovasc. Diabetol. 18, 146. https://doi.org/10.1186/s12933-019-0954-6 (2019).

54. Wiest, R. \& Garcia-Tsao, G. Bacterial translocation (BT) in cirrhosis. Hepatology 41, 422-433. https://doi.org/10.1002/hep.20632 (2005).

55. Lafuse, W. P. et al. Exposure to a social stressor induces translocation of commensal lactobacilli to the spleen and priming of the innate immune system. J. Immunol. 198, 2383-2393. https://doi.org/10.4049/jimmunol.1601269 (2017).

56. Hu, J. et al. Enteric dysbiosis-linked gut barrier disruption triggers early renal injury induced by chronic high salt feeding in mice. Exp. Mol. Med. 49, e370. https://doi.org/10.1038/emm.2017.122 (2017).

57. Zhang, J. et al. Thermally processed oil exaggerates colonic inflammation and colitis-associated colon tumorigenesis in mice. Cancer Prev. Res. (Phila) 12, 741-750. https://doi.org/10.1158/1940-6207.CAPR-19-0226 (2019).

58. Wells, C. L. Relationship between intestinal microecology and the translocation of intestinal bacteria. Antonie Van Leeuwenhoek 58, 87-93. https://doi.org/10.1007/BF00422722 (1990).

59. Nettelbladt, C. G. et al. Orally inoculated Escherichia coli strains colonize the gut and increase bacterial translocation after stress in rats. Shock 20, 251-256. https://doi.org/10.1097/01.shk.0000068324.41183.c2 (2003).

\section{Acknowledgements}

We thank Kayoko Kagaya and Hiromi Fujishima for excellent technical support. Language editing services were provided by ThinkSCIENCE, Tokyo, Japan.

\section{Author contributions}

S.K. designed the study, performed the majority of the experiments, analyzed the data, and wrote the manuscript; T.S. and M.K. performed experiments; H.F. provided helpful suggestions on experimental design; Y.Y. designed the study, supervised the project, and co-wrote the manuscript.

\section{Funding}

This study was supported in part by a Grant-in-Aid for Scientific Research from the Japan Society for the Promotion of Science (18H03171) and the Japan Agency for Medical Research and Development under Grant Number JP18ek0210111.

\section{Competing interests}

The authors declare no competing interests. 


\section{Additional information}

Supplementary Information The online version contains supplementary material available at https://doi.org/ 10.1038/s41598-021-88612-x.

Correspondence and requests for materials should be addressed to Y.Y.

Reprints and permissions information is available at www.nature.com/reprints.

Publisher's note Springer Nature remains neutral with regard to jurisdictional claims in published maps and institutional affiliations.

(c) (i) Open Access This article is licensed under a Creative Commons Attribution 4.0 International License, which permits use, sharing, adaptation, distribution and reproduction in any medium or format, as long as you give appropriate credit to the original author(s) and the source, provide a link to the Creative Commons licence, and indicate if changes were made. The images or other third party material in this article are included in the article's Creative Commons licence, unless indicated otherwise in a credit line to the material. If material is not included in the article's Creative Commons licence and your intended use is not permitted by statutory regulation or exceeds the permitted use, you will need to obtain permission directly from the copyright holder. To view a copy of this licence, visit http://creativecommons.org/licenses/by/4.0/.

(C) The Author(s) 2021 